\title{
Notas
}

\section{Del amor sublime en Aura}

\author{
Manuel PÉREZ MartíneZ*
}

Resumen:

Aunque la magia de Consuelo es doble (partenogénesis de Aura y anamnesis de Felipe), en términos de la ficción, sin embargo, esta magia tiene como base al amor. La belleza no resulta una explicación suficiente para el amor que Fuentes hace nacer entre el historiador y la bruja; pues si la belleza se anula, es necesario buscar otra razón que vaya más allá del hecho aparente que es la hermosura física: el amor sublime. En Aura, de Carlos Fuentes, tiene lugar el triunfo de la magia sobre la historia y el enfrentamiento de dos modelos de conocimiento: el académico y la imaginación.

Palabras clave:

Carlos Fuentes, literatura fantástica, amor y magia, historia y mito, erotismo escatológico.

Lo fantástico supone una presencia espectral suspendida entre el ser y la nada, dice Rosemary Jackson; deriva del latín phantasticus, que significa hacer visible o manifiesto algo que no lo es. Entre el ser y la nada o, mejor, entre lo que es y lo que no (porque ha sido o porque será) se encuentra el amor de Consuelo, la bruja-madre de Aura, novela con la que Carlos Fuentes continúa su exploración de lo fantástico, iniciada en Los días enmascarados en 1954 y que se prolonga hasta Instinto de Inez, publicada en 2001.

* Estudiante del Programa de doctorado en Literatura Hispánica del Colegio de México. 
En Aura es posible encontrar los mismos elementos que en Aspern Papers de Henry James, Great Expectations de Dickens, A Rose for Emily de Faulkner o La reina de espadas de Pushkin: un hombre trata de descubrir el secreto de una vieja y es engañado por una joven que vive con la vieja, aunque en Aura no son tres sino cuatro personajes, si contamos al general Llorente. En ese sentido, la novela de Fuentes está más cerca de "La cena", cuento de Alfonso Reyes, pues la relación triangular que establece el arquetipo desarrollado en aquellas obras se vuelve tanto en Aura como en "La cena" un rombo, un cruce de imágenes en espejo con la presencia de ese otro que vuelve del pasado y del más allá; en el caso de Aura, la presencia del pasado implica también la presencia del amor en tanto que éste es la fuerza que anula el tiempo histórico y propone una nueva realidad sobre el tiempo mítico circular.

Felipe Montero es un historiador marginal que conserva abandonado en el tintero un gran proyecto: la historia de las conquistas españolas de América, inicio del amor paradójico del que hemos nacido, la brutal posesión de la madre india y agrícola por el padre de hierro, espada y cruz. El magnífico salario que le ofrece la señora Consuelo Llorente por terminar de redactar las memorias de su esposo le permitiría dedicarse después todo un año a su obra historiográfica; Felipe pasa entonces, en su encuentro con la magia, de la seducción del sueldo a la seducción amorosa.

La anciana sonreirá, incluso reirá con su timbre agudo y dirá que le agrada tu buena voluntad y que la joven te mostrará tu recámara, mientras tú piensas en el sueldo de cuatro mil pesos, el trabajo que puede ser agradable porque a ti te gustan estas tareas meticulosas de investigación, que excluyen el esfuerzo físico, el traslado de un lugar a otro, los encuentros inevitables y molestos con otras personas (21).

Y más tarde, siempre por la voz del narrador, Felipe piensa "si el precio de tu futura libertad creadora es aceptar todas las manías de esta anciana, puedes pagarlo sin dificultad" (34). Sin embargo, es atrapado por la circunstancia y pasa de una exploración del pasado ajeno a la enajenación por éste de su futuro; de la summa histórica que pretendía a las memorias individuales donde se encuentra a sí mismo. Con ello no sólo tiene lugar el triunfo de un género sobre otro, sino también el enfrentamiento de dos modelos de conocimiento: el académico y el de la imaginación, el racional y el 
intuitivo que conecta con el mundo semiótico primigenio, instante eterno donde el caos constantemente transita al cosmos, punto de unión y separación, cruce amoroso.

La novela es mito, lenguaje y estructura, afirmó Fuentes en $\mathrm{La}$ nueva novela hispanoamericana, y en un texto publicado en 1949 en la revista Hoy "¿Pero usted no sabe aún lo que es el Basfumismo" (cit. por Merino 135), había dicho ya "para ser el hombre debe asesinar al tiempo [...] El hombre actual vive, no para él, sino para su proyección en el futuro. No existe el hombre. Existe su participación en el tiempo" (cit. por Ordiz 25). Para lograr consumar este asesinato del tiempo, el hombre -el espécimen masculino, atado a su deber simbólico, patriarcal y lineal- precisa de la mujer, que en toda la obra de Carlos Fuentes es puerta de entrada a una realidad distinta, a un mundo alterno que anula el tiempo. El epígrafe de Aura, tomado de La Sorcière de Jules Michelet, no puede ser más denotativo de esta condición especial de la mujer en esta obra de Fuentes:

El hombre caza y lucha, la mujer intriga y sueña: es la madre de la fantasía, de los dioses. Posee la segunda visión, las alas que le permiten volar hacia el infinito del deseo y de la imaginación... Los dioses son como los hombres: nacen y mueren sobre el pecho de una mujer...

Las coincidencias con el pensamiento de Michelet no sólo están presentes en La Sorcière, sino también en La mujer, obra en la que seguramente Fuentes encontró elementos para fortalecer su concepción de que la mujer continúa la labor de la naturaleza: "Los frutos efímeros que el otoño arroja a torrentes para perderse, ella los fija, los encanta" (101). Cómo no pensar en Consuelo y sus artes mágicas cuando en La mujer Michelet dice, respecto al milagro de la vida en la flor: "Es una gran injusticia usarla por el placer pasajero de un adorno sin valor, como una flor de papel, y al mismo tiempo olvidar la maravilla real, el milagro progresivo escondido en el pequeño santuario, la sublime operación de futuro y de inmortalidad por la cual cada año la vida escapa y se ríe de la muerte" (95-96), o bien "No abandona [la naturaleza] lo que le es tan necesario: lo atrae con su amor, lo transforma con su deseo, y le da el beneficio de la amable metamorfosis. Nos aspira al vegetar, y nos espira al florecer. Para el cuerpo tanto como para el alma, morir es vivir [...] La muerte es una flor" (308). 
La flor marchita bien puede ser Consuelo, que logra, por el amor, dar vida nueva a sus pétalos resecos y hacer que Felipe recuerde quién en verdad es. En realidad la magia de Consuelo es doble: en principio sólo Felipe y ella "existen", el general Llorente y Aura no pertenecen a este plano de realidad; ello a pesar de que el lector pueda asociar con mayor facilidad a Felipe con Aura y a Consuelo con Llorente. Con el primer hechizo logra Consuelo la partenogénesis, el parto mágico de sí misma cuyo fruto es Aura, la proyección de su juventud; con el segundo, la anamnesis de Felipe, el recuerdo verdadero de su naturaleza circular, cuando se descubre como Llorente en una antigua foto de Consuelo donde ella es Aura. Es decir, Aura es la juventud de Consuelo y Felipe la del general:

caes agotado sobre la cama, te tocas los pómulos, los ojos, la nariz, como si temieras que una mano invisible te hubiese arrancado la máscara que has llevado durante veintisiete años: esas facciones de goma y cartón que durante un cuarto de siglo han cubierto tu verdadera faz, tu rostro antiguo, el que tuviste antes y habías olvidado. ${ }^{1}(59)$

Tenemos pues dos personajes en un encuentro amoroso que sólo es posible por la magia de la partenogénesis, gracias al cotidiano, solitario y oscuro trajinar de Consuelo, por años, encerrada en esa casa de la calle Donceles, cocinando yerbas, conjurando por el fin del mundo, sacrificando chivos en la cocina hasta envejecer de puro amor y de tiempo, y lograr finalmente tener a punto el instrumento del gran hechizo, la proyección de su juventud: Aura. Con ella es posible encontrar, retener y despertar a su esposo muerto, lograr la gran magia del reencuentro por anamnesis.

${ }^{1}$ El folclor mitológico sobre la amnesia es antiguo. Entre los griegos "there is a difference between memory (mnemne) and recollection (anamnesis)", dice Mircea Eliade (Mitos y realidad, p. 119), donde a las dos clases de memoria, la cosmogónica y la histórica, digamos, corresponden dos clases de olvido; la anamnesis viene a ser el recuerdo por unificación de los fragmentos de memoria de las encarnaciones; más que recuerdo estructurado, es epifanía. Entre los hindúes se "recuerda" al más conocido maestro yogui de la Edad Media, Matsyendranâth, quien se enamoró de la reina de Ceylán y fue a vivir a su palacio olvidando su identidad; allí el yogui fue hecho prisionero nada menos que por las mujeres del país de Kadali. Finalmente, su discípulo Gorakhanât, movido por el amor a su maestro se disfraza de bailarina y logra hacer que recuerde su identidad verdadera por medio de danzas y canciones enigmáticas. En ambas 
Pedro Cátedra llama Philocaptio al concepto medieval de atracción amorosa, y especifica tres tipos: la concupiscencia, que es resultado de la mera visión de la mujer bella; la tentación de la lujuria, en la que coadyuva el demonio; y, finalmente, la que supone la intervención de la magia. La bruja medieval de La Sorcière y Consuelo hacen uso de su arte para lograr captar el afecto de su hombre, aun cuando para ello sea necesario pedir que el mundo muera y despertar a un muerto: "-Llega, Ciudad de Dios; suena, trompeta de Gabriel; ¡Ay, pero cómo tarda en morir el mundo!" (28). No es en realidad Consuelo una practicante de la magia negra, nigromancia, sino de la necromancia, esto es, la magia con los muertos.

Pero pedir que muera el mundo es una brujería cuyos efectos trascienden las meras intenciones de Consuelo, aunque ello sea necesario para volver a mirarse ojo a ojo con su esposo; es una petición que implica la destrucción del sentido histórico, lineal, de los acontecimientos. Esta magia pues, coherente con su naturaleza, no se sujeta a las fronteras del texto sino que el hechizo argumental, fabulístico y discursivo se expande en sendas direcciones y conmueve, extraña, la noción acostumbrada del devenir. En términos de la ficción, sin embargo, la magia fundamental en Aura sigue siendo amorosa.

Se ha dicho que una de las características de lo fantástico es la ausencia de explicación de los hechos sobrenaturales, el suspenso sobre un acontecimiento que nos intriga o nos niega. Aura puede ser leída como un texto paradigmático de lo fantástico partiendo de que es fiel a las tres condiciones que propuso Todorov para definir el género. En primer lugar, un inicio realista, necesario para la construcción del efecto fantástico, pues el texto obliga al lector a considerar el mundo y la historia de Felipe Montero como reales: la peripecia de un joven historiador con pocas posibilidades de trascendencia, encerrado en la monotonía de las clases que imparte en una escuela secundaria y lejos de sus sueños de escribir la gran obra de su vida. En segundo lugar, los hechos en que se ve envuelto se encuentran en la frontera entre lo natural y lo sobrenatural, y no se ajustan a la certidumbre de lo conocido ni a la permisividad de lo maravilloso; es decir, no pueden ser explicados sin vacilación. ${ }^{2}$ Finalmente, una construcción indicial nos acerca al advenimiento del hecho fantástico: los ojos de Saga, la coneja, rojos como el infier-

tradiciones, el olvido es equivalente a la ignorancia, la esclavitud y la muerte.

2 Esta vacilación en la interpretación de los sucesos es sufrida en primera instancia por el propio personaje y, luego, por el lector gracias al artificio de la escritura, sobre todo al ser interpelado constantemente por el narrador que 
no, son indicio del efecto hipnótico que tendrán después sobre Felipe los ojos de Aura, verdes como el color de Satán, y que no son sino la proyección bella y joven de los ojos marchitos de Consuelo que lograrán que Felipe vea sólo lo que ella desea.

Cabe preguntarse aquí si la magia de Consuelo tiene explicación, a lo que en principio puede responderse que no, partiendo de que el autor ha pretendido un efecto fantástico; sin embargo, me parece que sí tiene causa: el amor, pero ¿y al amor qué lo explica? Casi con iguales limitaciones, sólo es posible decir que el amor tiene por causa primera la belleza. Octavio Paz, siguiendo en parte el pensamiento platónico, dice que "el amor es una de las formas en que se manifiesta el deseo universal y consiste en la atracción por la belleza humana" (La llama doble 42-43). Sin embargo, la belleza sola no termina por explicar al amor pues si, como sucede a Felipe frente a Aura-Consuelo, la belleza se anula, es necesario buscar otra razón que vaya más allá del hecho aparente que es la hermosura física: “-mientras más pienses en ella, más tuya la harás, no porque pienses en su belleza y la deseas, sino porque ahora la deseas para liberarla: habrás encontrado una razón moral para tu deseo; te sentirás inocente y satisfecho" (37).

Aura le había dicho a Felipe, durante la segunda y definitiva entrega:

- ¿Me querrás siempre?

- Siempre, Aura, te amaré para siempre.

- ¿Siempre? ¿Me lo juras?

- Te lo juro.

- ¿Aunque envejezca? ¿Aunque pierda mi belleza? ¿Aunque tenga el pelo blanco?

-Siempre, mi amor, siempre.

- ¿Aunque muera, Felipe? ¿Me amarás siempre, aunque muera? (p. 49).

Tiene razón Aura en pedir tal correspondencia, pues su otro yo, Consuelo, fue capaz de amar al otro Felipe, el antiguo, al general Llorente, aún en su muerte, con tanta intensidad que pudo traerlo del más allá y hacer realidad sus anticipaciones: "Je pense que tu seras toujours belle, même dans cent ans" (43), dice Llorente en sus memorias. Por eso Felipe debía amarla en cualquier circunstancia, pues, como agrega Octavio Paz "su objeto [del amor] tampoco es simple y cambia sin cesar. El amor es algo más que atracción por la belleza humana, sujeta al tiempo, la muerte y la corrupción" ( $\mathrm{La}$ 
llama doble 43). El amor es distinto del erotismo y de la sexualidad, pues en todo encuentro amoroso se precisa de la imaginación y no sólo del deseo. Por imaginación y deseo, Consuelo tienta a Dios, como dice Llorente al final de sus memorias: "Consuelo, pobre Consuelo... Consuelo, también el demonio fue un ángel, antes..." (57).

Si el amor femenino de Consuelo es constante hasta vencer a la muerte, el de Felipe debe ser sublime para vencer el derrumbe de la belleza física. Kant, con tono patriarcal, afirma que la belleza es una cualidad naturalmente femenina: "hay en el carácter de este sexo rasgos particulares que lo diferencian claramente del nuestro y le hacen distinguirse principalmente por la nota de lo bello" y, continúa, lo sublime (propio del sexo masculino) conmueve, lo bello encanta (43). Sin duda, la belleza de Aura encantó a Felipe, pero el amor de Consuelo lo conmovió, lo conmocionó al punto de volverlo otro, de lograr que se encontrase otro. En El banquete, Platón escribe que Diotima aconseja a Sócrates respecto a estos asuntos: "si la hermosura está en muchas formas y personas, ¿por qué no amarla en ella misma?, ¿y por qué no ir más allá de las formas y amar aquello que las hace hermosas: la idea?" (cit. por Paz 44).

Este amor sublime es lo que explica el acto final de aceptación de la no belleza en la amada por parte de Felipe, que es el punto más alto de la nota mágica; explica el amor a pesar de la anulación de la belleza. El amor sublime es, por tanto, la causa teleológica de la magia que en sesenta años ha venido preparando Consuelo, aunque no es explicación del hecho mágico-literario en sí, pues éste queda siempre en el terreno de la incertidumbre, entre lo que no es y lo posible, mientras conservamos nuestra visión lineal del mundo. En el momento en que ella se perdiere, en que aceptásemos la existencia del tiempo circular, ese otro tiempo del amor, el relato se convertiría en una enorme alegoría que representara el enfrentamiento cosmogónico fundamental que no explica pero sostiene al mundo: la coexistencia universal de los opuestos. Ésa es otra magia del texto, que surge del mero hecho de ficción.

Así termina Octavio Paz su tratado del amor:

El tiempo del amor no es grande ni chico: es la percepción instantánea de todos los tiempos en uno solo, de todas las vidas en un instante [...] Somos el teatro del abrazo de los opuestos y de su disolución, resuelto en una sola nota que no es de afirmación ni de negación sino de aceptación. ¿Qué ve la pareja, en el espacio de un parpadeo? La identidad de la aparición y la 
desaparición, la verdad del cuerpo y del no-cuerpo, la visión de la presencia que se disuelve en un esplendor: vivacidad pura, latido del tiempo.

Todo el arte mágico de Consuelo es un arte de seducción que inicia en el reconocimiento, desde el primer encuentro:

-Felipe Montero. Leí el anuncio.

- Sí, ya sé. Perdón no hay asiento.

-Estoy bien. No se preocupe.

-Está bien. Por favor, póngase de perfil. No lo veo bien. Que le dé la luz. Así. Claro. (16)

Luego vendrán los ojos de mar de Aura, que aparecerá por vez primera por la mano de Consuelo: "La señora se moverá por la primera vez desde que tú entraste a su recámara; al extender otra vez su mano, tú sientes esa respiración agitada a tu lado y entre la mujer y tú se extiende otra mano que toca los dedos de la anciana. Miras a tu lado y la muchacha está allí" (19). Inmediatamente después de verla, Felipe acepta el trabajo. Ha pasado de la indecisión a la sorpresa, luego a la aceptación gustosa. De igual forma pasará cuando estando sobre Aura, Felipe descubra bajo la luz de la luna que no es ella sino Consuelo; sólo que entonces la aceptación no es gustosa sino terrible. De los ojos de mar a las cuencas oscuras y arrugadas, y viceversa. De los ojos de Aura al "rostro de ojos vaciados [que, en el primer sueño de Felipe, antes del primer encuentro erótico] se acerca al tuyo, despiertas con un grito mudo, sudando, y sientes esas manos que acarician tu rostro y tu pelo, esos labios que murmuran con la voz más baja, te consuelan, te piden calma y cariño. Alargas tus propias manos para encontrar el otro cuerpo, desnudo" (37). El segundo sueño de Felipe es mucho más agresivo, frente al que también se defiende con un grito: Consuelo se acerca "moviendo su mano descarnada, avanzando hacia ti hasta que su rostro se pegue al tuyo y veas esas encías sangrantes de la vieja, esas encías sin dientes y grites y ella vuelva a alejarse" (44).

Cuando se ama a una mujer vieja la atracción física cesa y el amor se transforma, dice Octavio Paz: "el amor, cualquier amor, está hecho de tiempo y ningún amante puede evitar la gran calamidad [...] Como un remedio contra el tiempo y la seducción del amor, los budistas concibieron un ejercicio de meditación que consistía en imaginar el cuerpo de la mujer como un saco de inmundi- 
cias" (La llama doble 211). Este amor que nace al final de Aura al parecer no está hecho sólo de tiempo, al menos no del tiempo lineal del agotamiento y la corrupción, sino de eso y algo más.

El erotismo escatológico que antecede la anagnórisis, el reconocimiento final de Felipe, llega al fin. Como dos sueños, hay también dos anagnórisis, la primera cuando Felipe se descubre en el Llorente de las fotos y "escondes la cara en la almohada, tratando de impedir que el aire te arranque las facciones que son tuyas, que quieres para ti. Permaneces con la cara hundida en la almohada, con los ojos abiertos detrás de la almohada, esperando lo que ha de venir, lo que no podrán impedir" (59), y la segunda en el último abrazo que es más bien el primero: "Apartarás los labios de los labios sin carne que has estado besando, de las encías sin dientes que se abren ante ti [...] Hundirás tu cabeza, tus ojos abiertos, en el pelo plateado de Consuelo, la mujer que volverá a abrazarte cuando la luna pase" (62).

Los ojos renuentes bajo la almohada o entre el pelo de la mujer mientras la luna pasa y cumple de nuevo el ciclo. Este ciclo lunar parece ser evocado por las encarnaciones de Aura, "nunca he podido mantenerla a mi lado más de tres días" (61), le confiesa Consuelo a Felipe; ello recuerda lo que sobre la luna y sus ciclos ha dicho Eliade: "La luna, en efecto, mensura las periodicidades más sensibles, y los términos relativos a la luna son los que han servido en primer lugar para expresar la medida del tiempo. Los ritmos lunares marcan siempre una «creación» (luna nueva) seguida de un crecimiento (luna llena), de un decrecer y de una «muerte» (las tres noches sin luna)" (Imágenes y símbolos, 79). La luna resulta así el gran símbolo femenino que hace coincidir al erotismo y al tiempo.

En el encuentro erótico-escatológico de Felipe y Consuelo hay una rebeldía satánica contra el tiempo, una condición herética que salva y logra la eternidad en el instante, la eternidad del cosmos y sus ciclos naturales: "Se asomará la luna, antes de que el vapor oscuro vuelva a empañarla [...] Tú ya no esperarás. Ya no consultarás tu reloj" (60). Por el amor sublime, entonces, el tiempo y la corrupción son vencidos; una recurrente victoria de la magia sobre la historia. 


\section{Bibliografía}

Callan, Richard. "The Jungian Basis of Carlos Fuentes' Aura." Kentucky Romance Quarterly 18 (1971): 65-71.

Cátedra, Pedro. Amor y pedagogía en la Edad Media. Salamanca: Universidad, 1989.

Ceserani, Remo. Lo fantástico. Tr. Juan Díaz de Atauri. Madrid: Visor, 1999.

Colette, Marianela. “La fase del espejo, lo simbólico y lo imaginario en la novela Aura, de Carlos Fuentes." Revista Canadiense de Estudios Hispánicos 19 (1995): 281-98.

Durán, Gloria. La magia y las brujas en la obra de Carlos Fuentes. México: UNAM, 1976.

Eliade, Mircea. Myths and Reality. Nueva York: Harper and Row Publishers, 1963.

—. Imágenes y símbolos. Madrid: Taurus, 1999.

Fuentes, Carlos. Aura. México. Era, 2001.

—. Instinto de Inez. México: Alfaguara, 2001.

_. Obras completas. México: Aguilar, 1975.

Gallo, Marta. "Proyección de 'La cena', de Alfonso Reyes en Aura, de Carlos Fuentes." El cuento mexicano. Homenaje a Luis Leal. Ed. Sara Poot Herrera. México: UNAM, 1995.

García Gutiérrez, Georgina. Los disfraces: la obra mestiza de Carlos Fuentes. El Colegio de México, México, 2000.

- "Una lectura de Carlos Fuentes: Los días enmascarados, Aura." (Tesis doctoral). México: El Colegio de México, 1978. 
Jackson, Rosemary. Fantasy: The Literature of Subversion. Londres: Routhledge, 1988.

Kant, Immanuel. Lo bello y lo sublime. Tr. A. Sánchez Rivero y F. Rivera Pastor. Madrid: Espasa-Calpe, 1972.

Merino, Blanca. "Fantasía y realidad de Aura de Carlos Fuentes." Literatura Mexicana 2 (1991): 135-47.

Michelet, Jules. La mujer. México: Fondo de Cultura Económica, 1985.

La sorcière. Ed. Paul Viallaneix. París: Garnier-Flammarion, 1966.

Ordiz, Francisco Javier. El mito en la obra narrativa de Carlos Fuentes. León: Universidad, 1987.

Paz, Octavio. La llama doble. Amor y erotismo. México: Seix Barral, 1993.

Pérez, Genaro. "La configuración de elementos góticos en 'Constancia', Aura y 'Tlactocatzine en el jardín de Flandes' de Carlos Fuentes." Hispania 80 (1997): 9-20.

Quezada, Noemí. Amor y magia amorosa entre los aztecas. México: UNAM, 1984.

Thomas Dublé, Eduardo. "Hechicerías del discurso narrativo latinoamericano: Aura de Carlos Fuentes", vI jornadas Interdisciplinarias Sobre Religión y Cultura: "Magia y Religión”, Universidad de Chile, Santiago, 24-26 de agosto de 1998.

Todorov, Tzvetan. Introducción a la literatura fantástica. Tr. Silvia Delpy. México: Coyoacán, 1994. 